\title{
The effect of microstructure on tensile strength of high martensite dual-phase steels
}

\author{
T. Saatc1*, E. Salamci \\ Department of Mechanical Engineering, Gazi University, 06570 Maltepe, Ankara, Turkey
}

Received 28 June 2016, received in revised form 5 October 2016, accepted 6 October 2016

\begin{abstract}
In this work, different dual phase (DP) microstructures were produced in $15 \mathrm{CrNiMo} 7$ steel, in order to study the effect of martensite volume fraction (MVF), martensite morphology $(\mathrm{MM})$, and epitaxial ferrite (EF) on tensile strength behavior. Mechanical properties of five different DP steels have been investigated by carrying out tensile and hardness tests. By increasing the martensite content, both tensile and yield strengths increased. The presence of new ferrite caused a decrease in strength and increase in ductility. Fractography analysis after the tensile test was performed by using SEM.
\end{abstract}

Key words: high martensite, morphology, epitaxial ferrite, tensile strength, dual-phase steel

\section{Introduction}

Hard martensite and soft ferrite phases together compose DP steels, and they provide high strength and good ductility, compared to High Strength Low Alloy (HSLA) steels [1-3]. DP steels reduce automobile weight resulting fuel efficiency, which makes DP steels preferable in automobile parts. They are mainly produced by heating the low carbon hypoeutectoid steel between the $A_{\mathrm{c} 1}$ and $A_{\mathrm{c} 3}$ temperatures in the austenite plus ferrite phase field with subsequent rapid cooling in order to transform the austenite to martensite [4]. In addition to martensite, the microstructure may contain small amounts of other phases such as bainite, pearlite, EF, retained austenite depending on cooling rate [5].

Over the past few years, noticeable investigations have been directed toward microstructural development and mechanical properties of DP steels. Researchers investigated the effect of MVF, MM, and EF on yield strength, tensile strength, and strain hardening behavior of DP steels. Davies [6] reported that strength of dual phase structure is dependent on the ferrite grain size and the volume fraction of martensite. Sarwar et al. [7] observed that increasing the MVF raised the tensile strength and ductility and also increasing the EF content decreased tensile strength and increased ductility. Movahed et al. and Bag et al. $[8,9]$ investigated that an equal amount of ferrite and martensite have excellent mechanical properties regarding tensile strength and ductility, but a further increase in MVF was found to decrease tensile strength and ductility. Sarwar et al. [10] studied the effect of martensitic morphology and its distribution in a ferrite matrix on tensile properties of a low alloy steel. They developed two distinct microstructures; one consisted of continuous ferrite matrix with embedded islands of martensite (MD: martensite dispersed), the other was continuous martensite phase with embedded islands of ferrite (MC: martensite continuous). They reported that MC structure had a higher tensile strength as compared to MD structure. Tüzemen and Salamci [11] reported that increasing MVF and decreasing martensite size increased yield strength, tensile strength, and hardness. Sarwar et al. [12] examined specimens with $20-25 \% \mathrm{EF}$ and found they have low yield and tensile strengths but have superior ductility compared with specimens which were free of EF. Huppi et al. [4] reported that increasing EF content decreased tensile strength. Previous investigations have shown that ductility of DP steels increases with a small decrease in strength, as the EF content increases [12-14].

The present study is designed to examine the ten-

*Corresponding author: tel.: +90312 5823464; fax: +90312 2319810; e-mail addresses: saatci.tutku@gazi.edu.tr, saatcitutku@gmail.com 
Table 1. Chemical composition of the investigated steel (wt.\%)

\begin{tabular}{cccccccccccc}
\hline Components & $\mathrm{C}$ & $\mathrm{Si}$ & $\mathrm{P}$ & $\mathrm{S}$ & $\mathrm{V}$ & $\mathrm{Cr}$ & $\mathrm{Mn}$ & $\mathrm{Ni}$ & $\mathrm{Mo}$ & $\mathrm{Fe}$ & Balance \\
\hline
\end{tabular}

sile and strain hardening behavior of DP steels, with high MVF (65-86\%), different morphology (coarse, fiber), and $\mathrm{EF}(25 \%)$. In this work tensile and strain hardening behaviors of DP steel microstructures which are produced at three different intercritical annealing temperatures followed by rapid and slow cooling rates are investigated.

\section{Experimental procedure}

The chemical composition of the steel used in the present investigation is given in Table 1 . The material was a cylindrical bar which is $13 \mathrm{~mm}$ in diameter and $3 \mathrm{~m}$ in length, produced by hot rolling, stress relief annealing, and cold drawing steps, respectively. The bar was then cut into small pieces of $13 \mathrm{~mm}$ in diameter and $4 \mathrm{~mm}$ in height.

The critical annealing temperatures, $A_{\mathrm{c} 1}$ and $A_{\mathrm{c} 3}$, were identified as 715 and $820^{\circ} \mathrm{C}$, respectively, by using the following Andrew's empirical equations [15]:

$$
\begin{aligned}
A_{\mathrm{c} 1}= & 723-10.7 \mathrm{Mn}-16.9 \mathrm{Ni}+29.1 \mathrm{Si}+ \\
& +16.9 \mathrm{Cr}+290 \mathrm{As}+6.38 \mathrm{~W} \\
\mathrm{~A}_{\mathrm{c} 3}= & 910-203 \mathrm{C}^{1 / 2}-15.2 \mathrm{Ni}+44.7 \mathrm{Si}+ \\
& +104 \mathrm{~V}+31.5 \mathrm{Mo}+13.1
\end{aligned}
$$

Small specimens were subjected to different heat treatment procedures to produce DP microstructures as follows:

(i) intercritical annealing of the specimens at 755 , 785 , and $810^{\circ} \mathrm{C}$ for $25 \mathrm{~min}$ followed by water quenching (ICQ755, ICQ785, and ICQ810),

(ii) austenitization of the specimens at $900{ }^{\circ} \mathrm{C}$ for 25 min followed by quench water to obtain almost fully martensitic structure and after that re-annealing of the specimens at $785^{\circ} \mathrm{C}$ for 25 min followed by quench water (IMQ785),

(iii) intercritical annealing of the specimens at $810^{\circ} \mathrm{C}$ for $25 \mathrm{~min}$ followed by furnace cooling (ICFC810).

The heat treatment cycles are presented schematically in Fig. 1. Each specimen, namely ICQ755, ICQ785, ICQ810, IMQ785, and ICFC810 was coded according to the applied heat treatment procedures. The left-hand letters ICQ, IMQ, and ICFC represent intercritical quenching, intermediate quenching, and intercritical furnace cooling, respectively. The righthand numbers represent the ICAT.

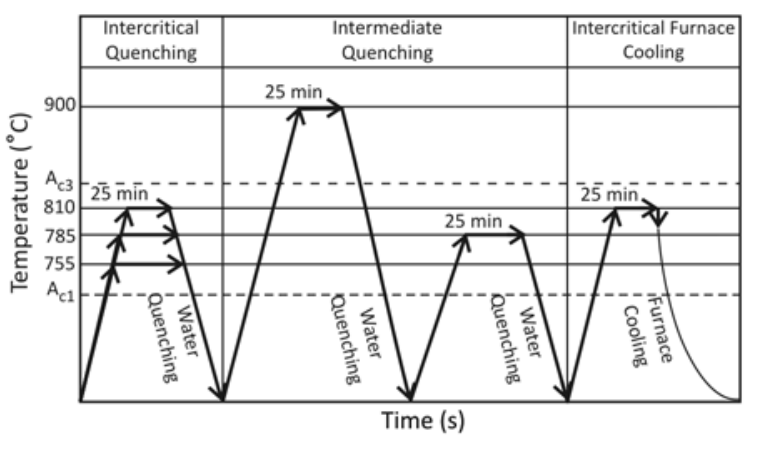

Fig. 1. Schematic representation of heat treatment cycles.

The heat treated samples were ground, polished, and etched in two different solutions according to the heat treatment cycles, for microstructural characterization by using a light microscope (OLYMPUS GX79) as follows:

(i) $2 \%$ nital (solution of $2 \%$ nitric acid in $98 \%$ methanol) for characterization of ferrite-martensite microstructures (ICQ755, ICQ785, ICQ810, and IMQ785),

(ii) $4 \%$ picral ( $4 \mathrm{~g}$ picric acid $+100 \mathrm{~mL}$ methanol) $50 \mathrm{~s}, 2 \%$ nital (solution of $2 \%$ nitric acid in $98 \%$ methanol) $4 \mathrm{~s}$, and alkaline chromate solution $(8 \mathrm{~g}$ $\mathrm{CrO}_{3}+72 \mathrm{~mL}$ pure $\mathrm{H}_{2} \mathrm{O}$, and $40 \mathrm{~g} \mathrm{NaOH}$ ) boiling at constant $120^{\circ} \mathrm{C}$ for $6 \mathrm{~min}$ [16], respectively, for characterization of retained ferrite-EF-martensite microstructures (ICFC810).

The volume fraction of phases was determined by using Image J software on etched metallographic sections (average of 10).

The hardness tests were performed on heat treated specimens, except for ICFC810, using DIGIROCK machine with diamond cone tip, starting load of $10 \mathrm{~kg}$, and total load of $150 \mathrm{~kg}$ in terms of Rockwell C. The hardness test of ICFC810 was performed with 1/16inch steel ball, starting load of $10 \mathrm{~kg}$, and total load of $100 \mathrm{~kg}$ in terms of Rockwell B. The results were then converted to HRC by using hardness conversion table. An average of 7 measurements was taken for each heat treated specimen.

Tensile tests were performed on heat treated specimens using WINWDW Universal test machine. Tensile test specimens were manufactured in accordance with the standard of TS EN ISO 6892-1 [17] as shown in Fig. 2. Three tensile specimens were tested for each microstructure, and average values were taken. 


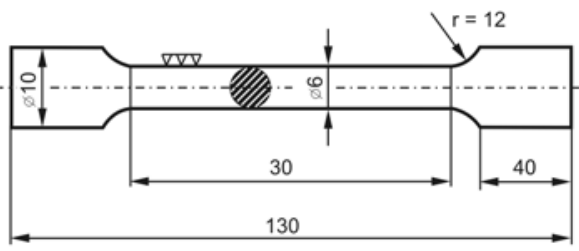

Fig. 2. Schematic of the tensile test specimen (dimensions are in millimeters).

The examination of fracture surfaces of the tensile specimen was carried out using scanning electron mi- croscope (SEM). Fracture surface examination of the samples was carried out using QUANTA 400F High Resolution (1.2 nm) SEM.

\section{Results and discussion}

\subsection{Microstructures}

Austenite at intercritical annealing temperatures transforms to martensite and EF depending on cooling rate. Optical micrographs of the ICQ755, ICQ785, and ICQ810 etched with $2 \%$ nital are displayed in
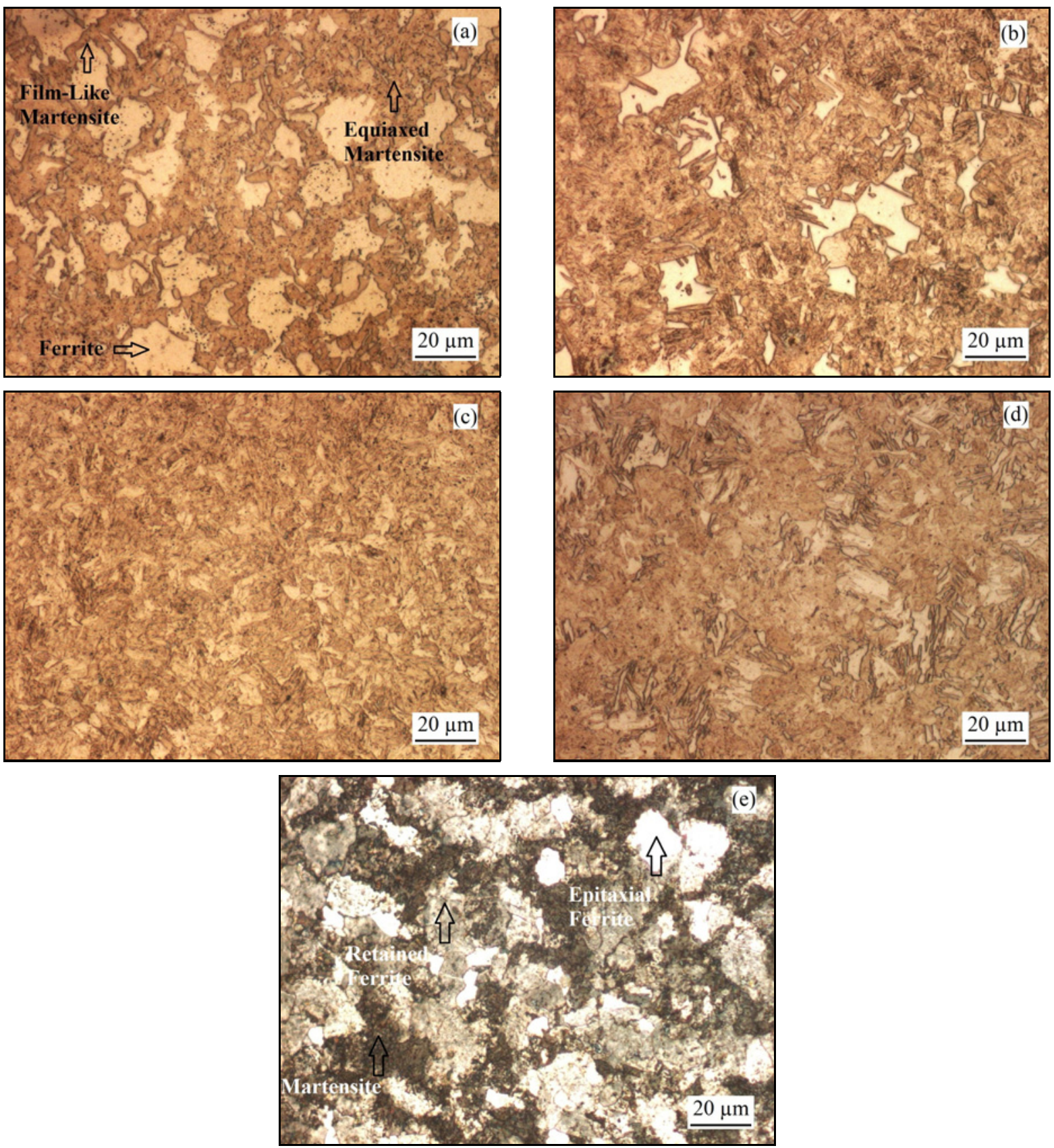

Fig. 3. (a) ICQ755, (b) ICQ785, (c) ICQ810, (d) IMQ785, and (e) ICFC810. 
Table 2. Microstructure and quantitative metallographic data for steel samples

\begin{tabular}{llcc}
\hline Specimen code & Microstructure & Volume fraction of martensite (\%) & Volume fraction of EF (\%) \\
\hline ICQ755 & Ferrite-network martensite & 65 & - \\
ICQ785 & Ferrite-network martensite & 76 & - \\
ICQ810 & Ferrite-network martensite & 85 & - \\
IMQ785 & Fibrous ferrite and martensite & 76 & - \\
ICFC810 & Ferrite-EF-martensite & 61 & 25 \\
\hline
\end{tabular}

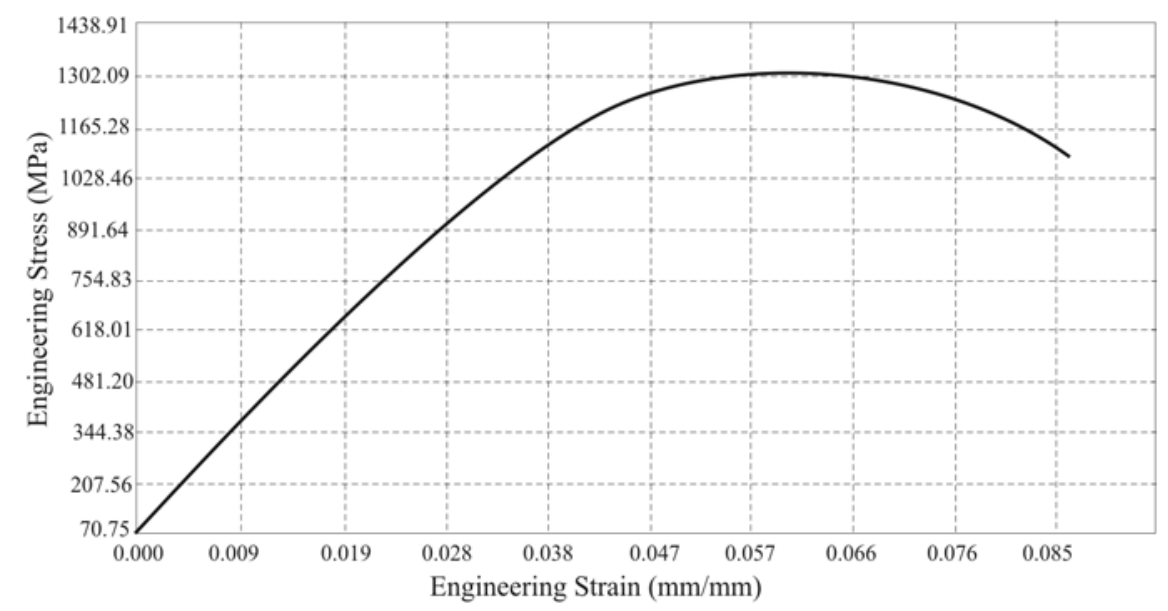

Fig. 4. Stress-strain curve of ICQ755.

Figs. $3 \mathrm{a}-\mathrm{c}$, respectively. The heat treating of the specimens directly to the intercritical temperature produced martensite network along the ferrite grain boundaries. It can be seen from Figs. $3 \mathrm{a}-\mathrm{c}$ that ferrite is surrounded by a ring of martensite. Such morphological distribution of martensite is termed as ring, chain or continuous network of martensite. The network model of the formation of martensite consists of the film-like and equiaxed grains to be joined [18]. The continuous martensite network forms after a certain amount of increase in MVF with increasing ICAT. Speich et al. [19] explained the network model of martensite. They found that the growth of austenite into ferrite was controlled by manganese diffusion in ferrite which is much easier along the grain boundaries. Thus, the austenite which transforms to martensite during quenching grows along ferrite grain boundaries.

On the other hand, the DP microstructure of IMQ785 sample is significantly different from that of ICQ755, ICQ785, and ICQ810 as represented in Fig. 3d. The microstructure of the standard quenched DP steel sample with almost fully martensitic initial microstructure consists of fine martensite distribution that surrounds ferrite grain boundaries.

Martensite was replaced by EF with the decreasing cooling rates. During the slow cooling rates, the austenite firstly transforms to new ferrite which grows epitaxially on the retained or intercritical ferrite with- out a nucleation step [4]. It has been shown that there is no structural interface between the two types of ferrite and the EF differs from the retained ferrite in terms of composition [20, 21]. Slower cooling from $810^{\circ} \mathrm{C}$ resulted in the formation of $\mathrm{EF}$ in addition to martensite. Retained ferrite and EF were distinguished by Lawson etchant. Fig. 3e shows the micrograph of the ICFC810 etched with $4 \%$ picral $+2 \%$ nital + alkaline chromate revealing martensite as black, EF white, and retained ferrite gray.

The results of the quantitative metallographic measurements of MVF and EF volume fraction are summarized in Table 2.

In the present study, three types of microstructures were produced: one with ferrite-network martensite structure produced by ICQ which varies an amount of phase constituents and phase compositions, the other with ferrite-fiber martensite structure produced with IMQ, and the other one with ferrite-martensite-EF structure produced with ICFC.

The MVF increased with increasing the ICAT as shown in Table 2. This can be explained by lever rule. MVF of ICQ755, ICQ785, and ICQ810 are found to be 65,76 , and $85 \%$. Although the specimens ICQ755 and IMQ785 contained a constant amount of martensite, they had different microstructures such as a network or fibrous martensite. This difference may be due to their distinct initial microstructures. Slow cooling 


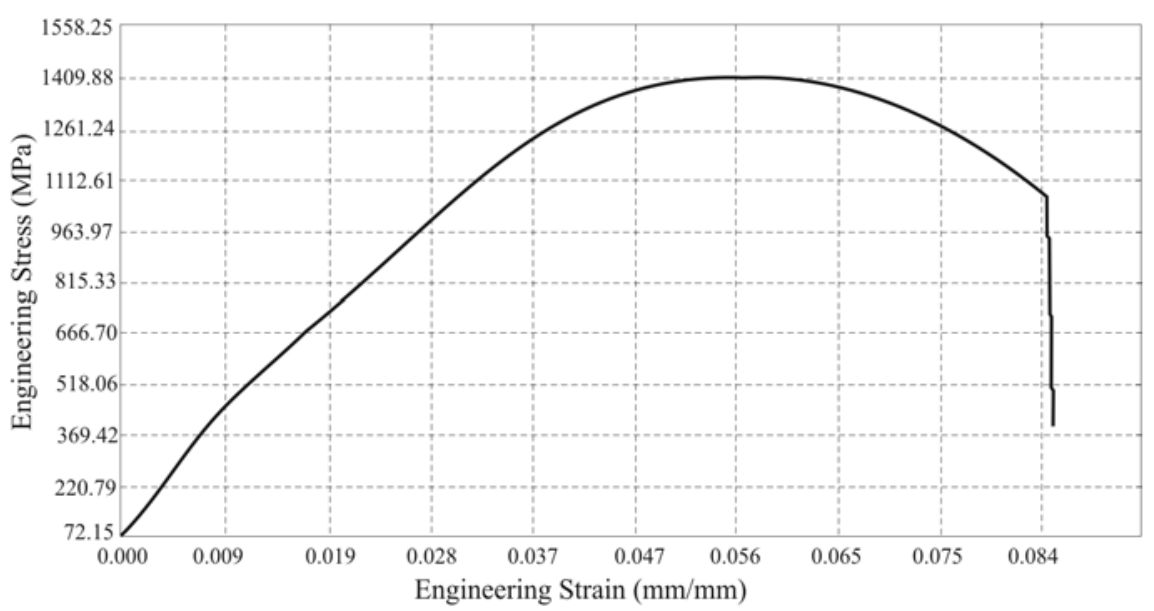

Fig. 5. Stress-strain curve of ICQ785.

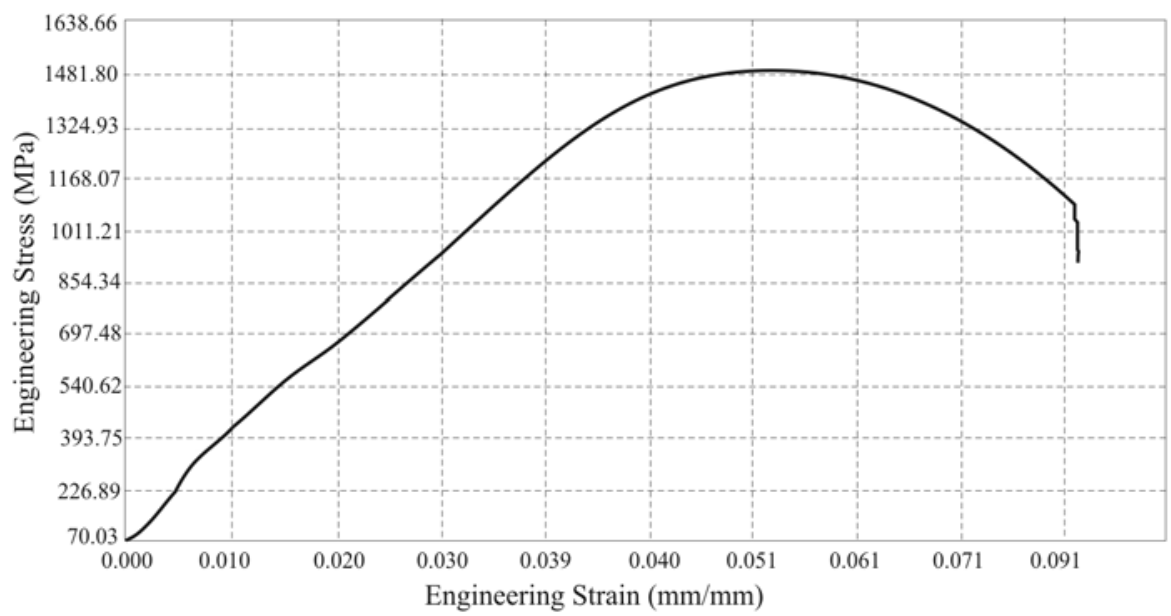

Fig. 6. Stress-strain curve of ICQ810.

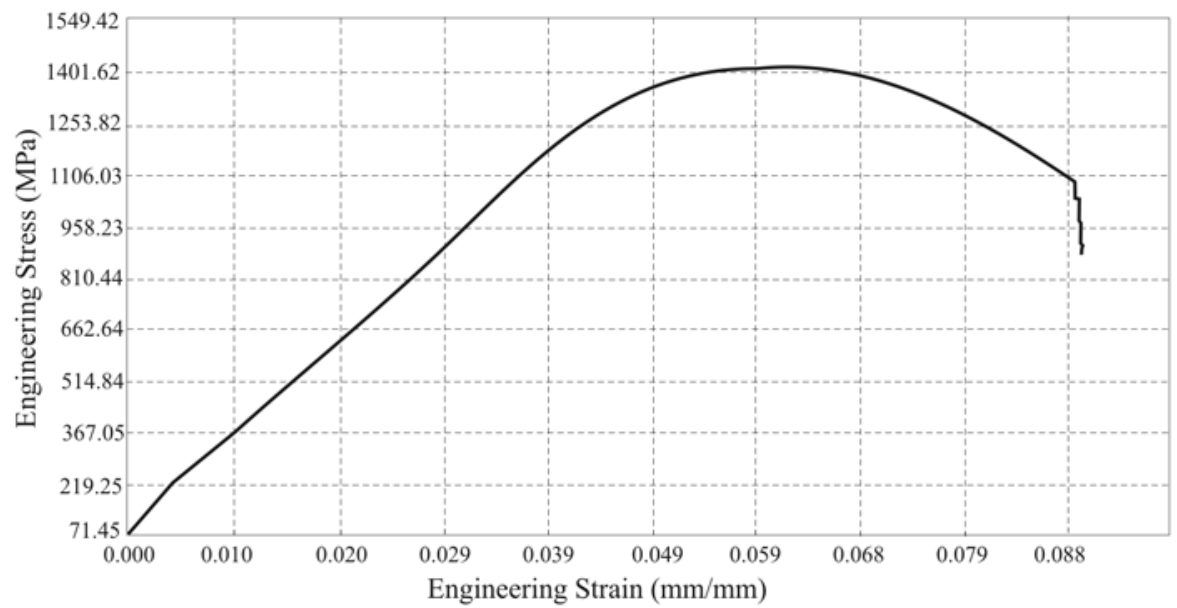

Fig. 7. Stress-strain curve of IMQ785.

in the furnace after intercritical annealing at $810^{\circ} \mathrm{C}$, $25 \mathrm{~min}$, resulted in the formation of $25 \% \mathrm{EF}$ with $61 \%$ martensite and $14 \%$ retained ferrite.

\subsection{Mechanical properties}

The effect of various heat treatment procedures on 


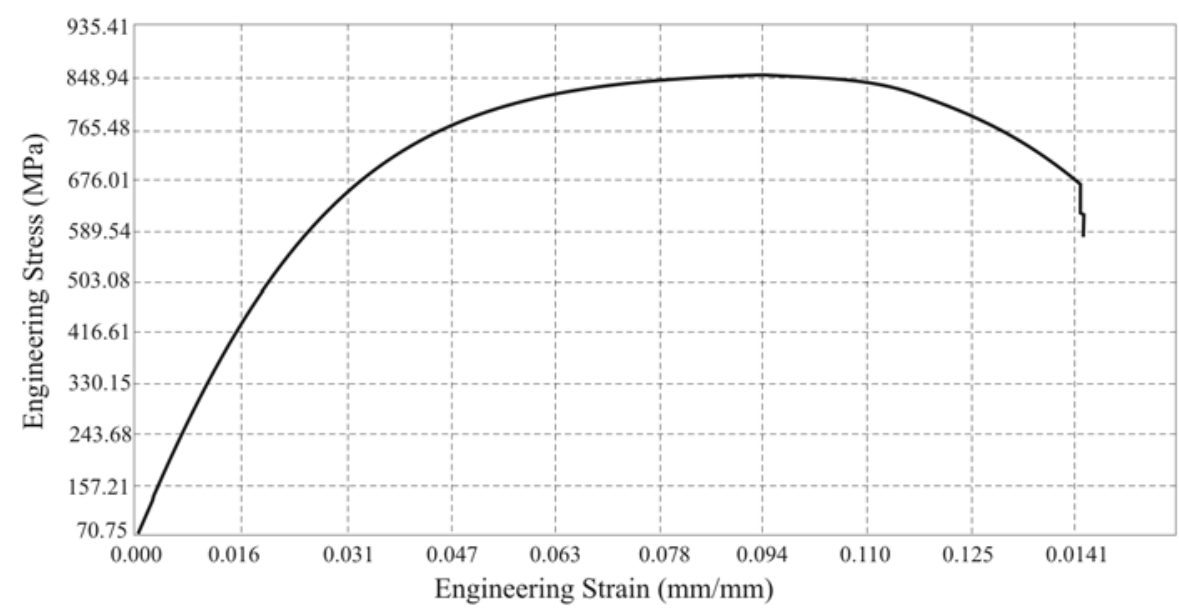

Fig. 8. Stress-strain curve of ICFC810.
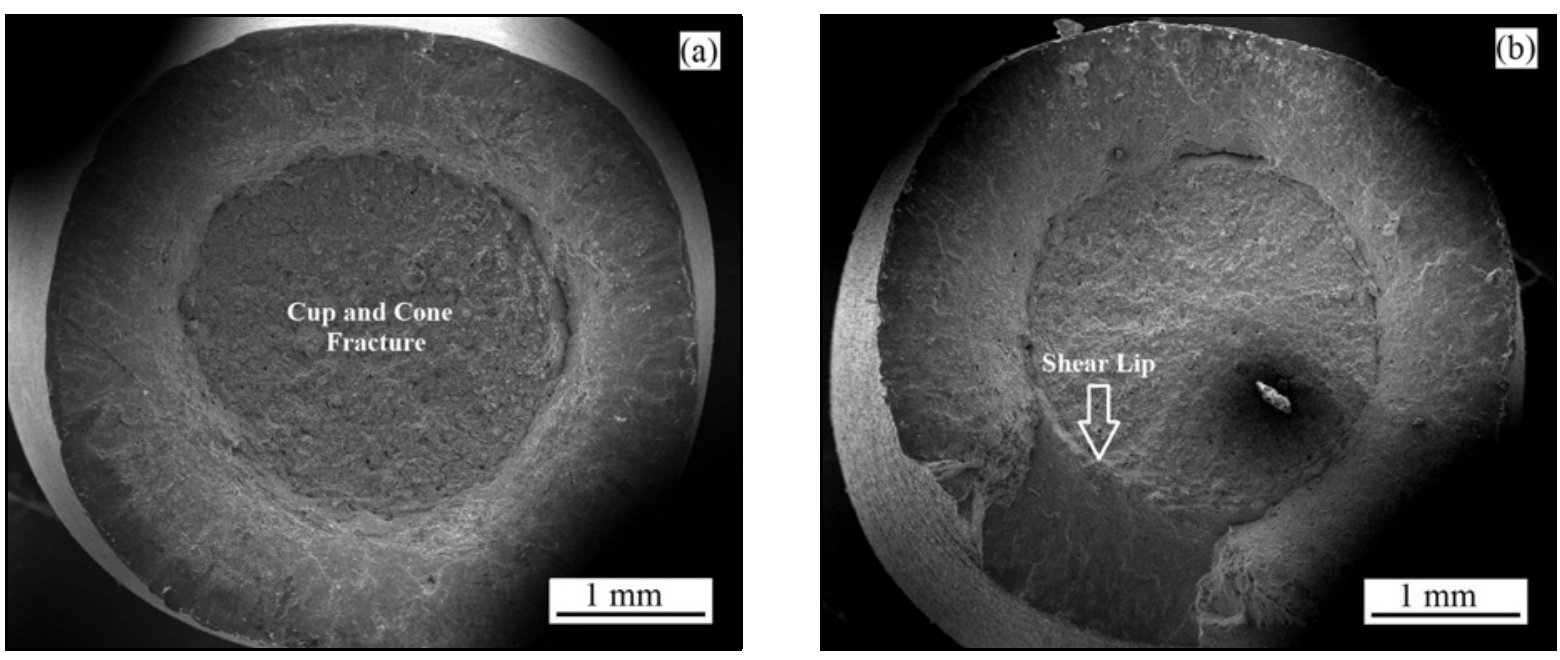

Fig. 9. (a) Cup and cone fracture (ICQ785), (b) shear lip (IMQ785).

Ta ble 3. Average room temperature hardness and tensile test results

\begin{tabular}{lccccc}
\hline Specimen code & Hardness (HRC) & $\begin{array}{c}0.2 \% \text { yield strength } \\
(\mathrm{MPa})\end{array}$ & $\begin{array}{c}\text { Ultimate tensile strength } \\
(\mathrm{MPa})\end{array}$ & $\begin{array}{c}\text { Total elongation } \\
(\%)\end{array}$ & $\begin{array}{c}\text { Toughness } \\
\left(\mathrm{MJ} \mathrm{m}^{-3}\right)\end{array}$ \\
\hline ICQ755 & 35.5 & 1197 & 1267 & 8.60 & 76 \\
ICQ785 & 42.9 & 1380 & 1430 & 8.67 & 84 \\
ICQ810 & 44.9 & 1410 & 1477 & 9.20 & 89 \\
IMQ785 & 44.4 & 1370 & 8313 & 9.00 & 83 \\
ICFC810 & $\approx 21.2$ & 682 & 833 & 14.23 & 87 \\
\hline
\end{tabular}

the mechanical properties of the heat treated steels was studied by hardness and tensile tests. Stress-strain curves are depicted in Figs. 4-8. The room temperature mechanical properties of the DP steels are summarized in Table 3.

Tensile and hardness data of ICQ DP steels (ICQ755, ICQ785, and ICQ810) indicate that the hardness, $0.2 \%$ yield strength (YS), ultimate tensile strength (UTS), total elongation, and toughness (the area under the stress-strain curve) increased as MVF increased. Similar results have been reported by Sarwar et al. [7]. Both increases in tensile strength and ductility could be attributed to the low carbon content of martensite with increasing ICAT. Also, connectivity of martensite plays an important role to improve the strength and ductility of material as reported by Sarwar et al. [10]. This is also consistent with the main characteristic of DP steels known as a good combina- 

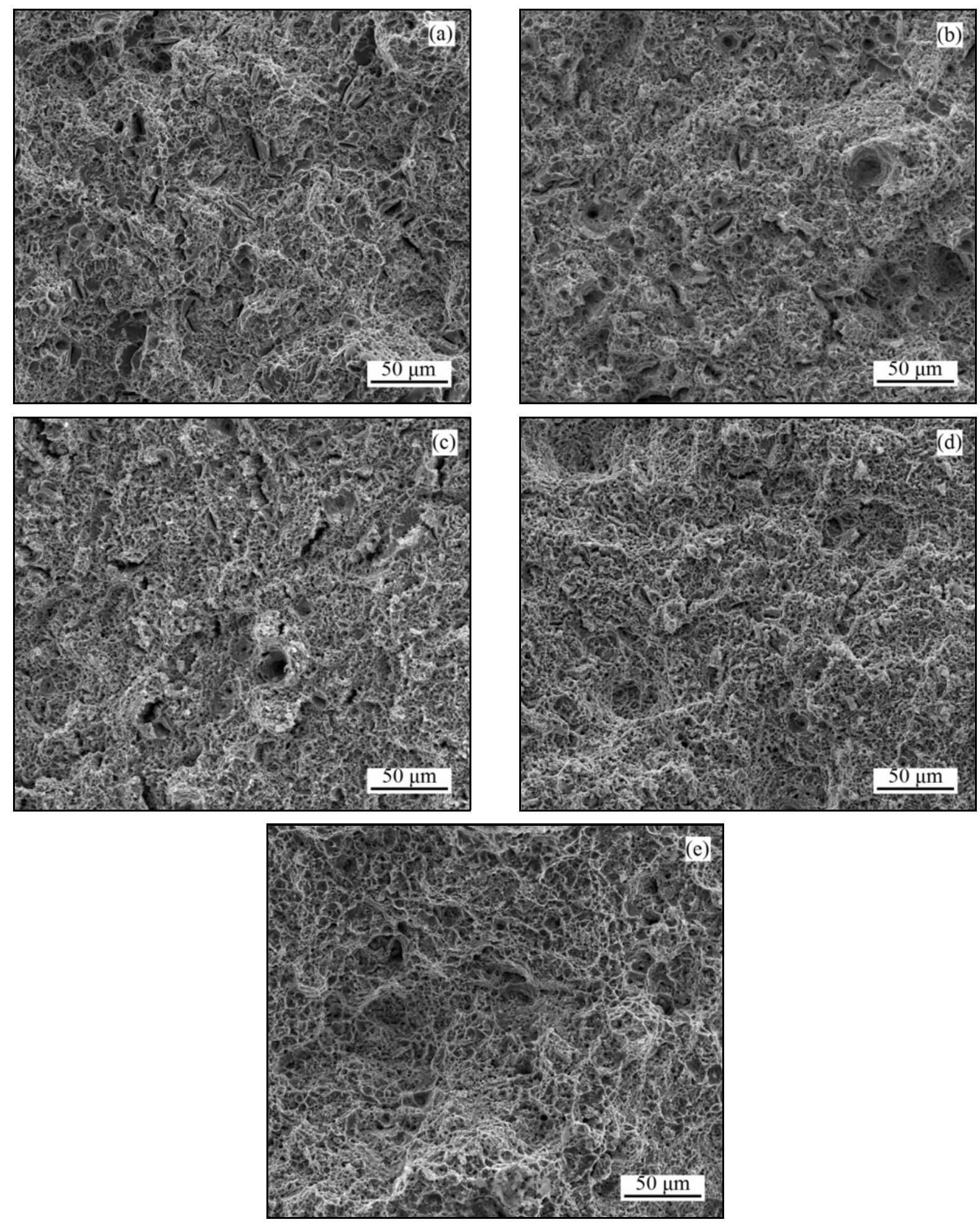

Fig. 10. Tensile fractography photographs of (a) ICQ755, (b) ICQ785, (c) ICQ810, (d) IMQ785, and (e) ICFC810.

tion of strength and ductility, which provides a good stress transfer between martensite and ferrite phases.

DP steel IMQ785 with fibrous martensite showed a bit lower values of the YS and UTS than ICQ785. Predictably, the percentage of total elongation value for ICQ785 is lower than that of IMQ785 and is in line with the previous work reported by Bag et al. [9]. They reported that UTS increases by increasing the MVF up to approximately $50 \%$ and then decreases with further increase in the MVF. According to Bag et al., the model developed on the basis of a rule of the mixture is inadequate to predict the tensile strength of 

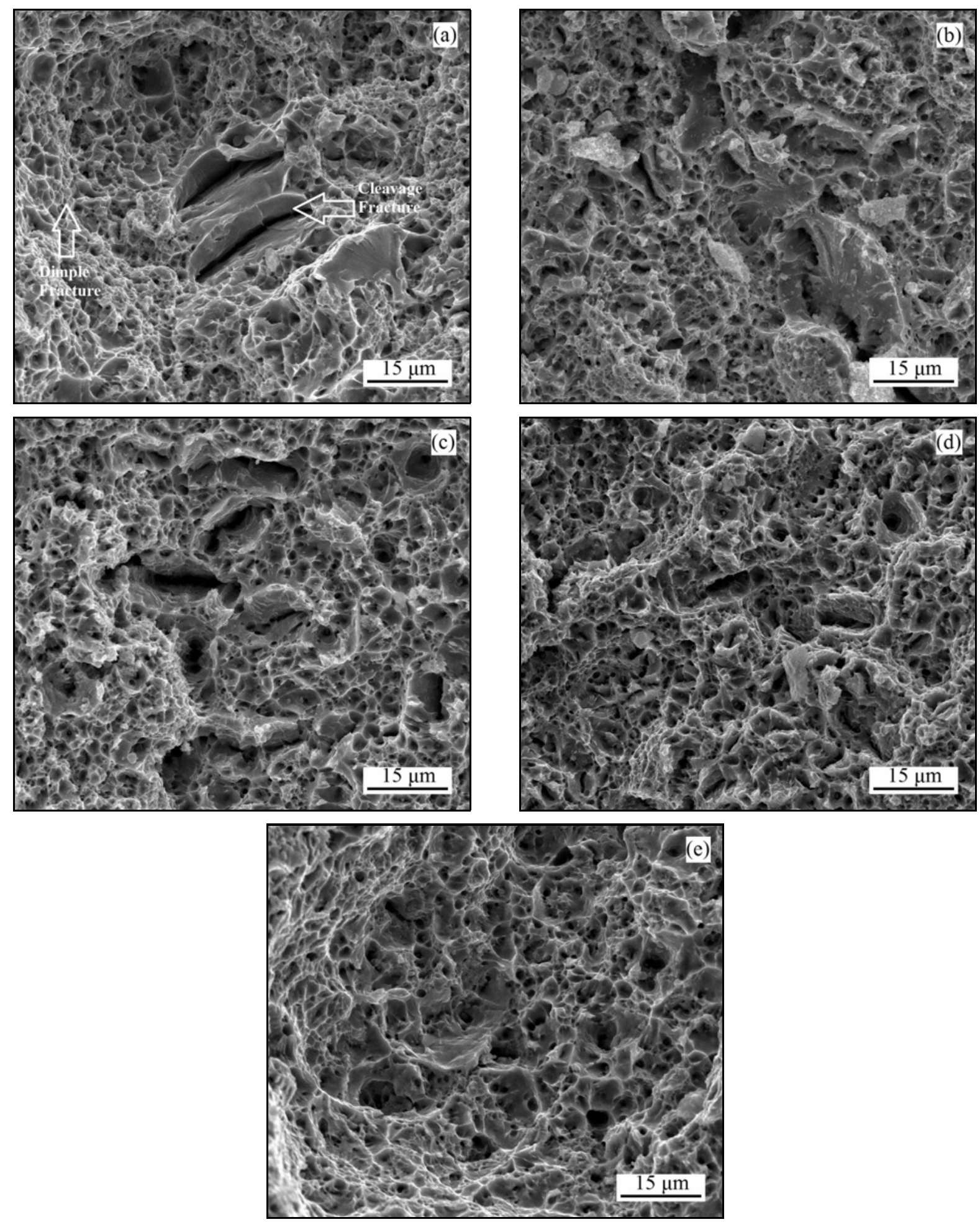

Fig. 11. High magnification tensile fractography photographs of (a) ICQ755, (b) ICQ785, (c) ICQ810, (d) IMQ785, and (e) ICFC810.

a specimen containing more than $50 \%$ of martensite and there is no linear relation between $\sigma_{\mathrm{TS}, \mathrm{DP}}$ and $v_{\mathrm{m}}$.

According to the rule of mixture, the tensile strength of DP steels $\left(\sigma_{\mathrm{TS}, \mathrm{DP}}\right)$ can be written as Eq. (3):

$$
\sigma_{\mathrm{TS}, \mathrm{DP}}=\sigma_{\mathrm{TS}, \mathrm{m}} v_{\mathrm{m}}+\sigma_{\mathrm{TS}, \mathrm{f}}\left(1-v_{\mathrm{m}}\right)
$$

where $\sigma_{\mathrm{TS}, \mathrm{m}}$ is the tensile strength of the martensite, $\sigma_{\mathrm{TS}, \mathrm{f}}$ is the tensile strength of the ferrite and $v_{\mathrm{m}}$ is MVF. 
Therefore, they developed a new theory based on the mean free path of ferrite and the mean free path of martensite to explain the unusual tensile behavior of high martensite DP steels. In this work, it seems that this theory could be used to clarify the decrease in the YS and the UTS values of IMQ785.

As can be seen from Table 3, ICFC810 steel shows the highest ductility and toughness and the lowest YS and UTS of all steel samples investigated in the present study. The specimens ICQ755 and ICFC810 have the almost constant amount of martensite; even the specimen ICFC810 was produced by furnace cooling. This is probably due to high hardenability of the present steel and high ICAT. The specimen ICFC 810 contains $61 \%$ and $25 \%$ MVF and EF, respectively. The specimen ICQ755 contains almost the same amount of martensite $(65 \%)$ and is free of EF. Although both specimens have the nearly constant amount of martensite, because of very high cooling rates, no EF formation was observed in ICQ755. As compared with ICQ755, significantly lower hardness, YS, and UTS and higher toughness and ductility were observed in ICFC810 as shown in Table 3. This has been related to the existence of EF in ICFC810. Similar results have been reported previously $[12,20]$.

\subsection{Tensile fractography analysis}

Cup and cone fracture mode observed on tensile fractography surfaces for all DP steels is shown in Fig. 9. Generally, there are two fracture modes in tensile fracture surfaces. One is cleavage, and the other one is dimple fracture mode. These two stages are depicted in Fig. 11a, showing the fracture surface SEM microphotograph of ICQ755. EF containing ICFC810 showed only dimple rupture mode and all the other DP steels showed mixed dimple and cleavage rupture modes.

As can be seen from Figs. 10a-c, ICQ755, ICQ785, and ICQ810 have large deep cleavage holes. Increasing MVF increased cleavage hole size. These holes are thought to be formed by fracture of martensite (no round holes) and inclusions (round holes). IMQ785 have less and thinner cleavage fracture regions when compared to ICQ785, as shown in Figs. 15b-d, respectively. ICFC810 with $25 \% \mathrm{EF}$ has only dimple fracture mode, whereas ICQ755 with the same amount of MVF has coexisting dimple and cleavage fracture modes as shown in Figs. 11a-e, respectively.

\section{Conclusions}

The main conclusions drawn on the basis of the experimental results are summarized as follows:

- Film-like and equiaxed martensite were produced by intercritical quenching. Fiber martensite was pro- duced by intermediate quenching. EF was produced by slow furnace cooling.

- MVF increased with increasing ICAT.

- Increasing MVF increased hardness, YS, UTS, fracture elongation, and toughness.

- As the MM changed the form from coarse to fiber, hardness and fracture elongation increased, YS and UTS slightly decreased, and toughness remained almost the same.

- New ferrite caused a decrease in hardness, YS, and UTS but provided a substantial increase in fracture elongation and toughness.

- Coexisting cleavage and dimple rupture modes are observed for all DP steels except ICFC810.

\section{Acknowledgement}

This research was supported by the Gazi University Scientific Research Projects Unit with project number of 06/2013-06.

\section{References}

[1] Rashid, M. S.: GM 980X-A Unique High Strength Sheet Steel with Superior Formability. SAE Technical Paper 1976.

[2] Davies, R. G., Magee, C. L., Buck, R. M.: Structure and Properties of Dual-Phase Steels. Eds.: Kot, R. A., Morris, J. W. New Orleans, AIME 1977.

[3] Coldren, A., Tither, G.: JOM, 30, 1978, p. 6. doi:10.1007/BF03354351

[4] Huppi, G., Matlock, D., Krauss, G.: Scripta Metallurgica, 14, 1980, p. 1239 . doi:10.1016/0036-9748(80)90264-1

[5] Zhang, C., Cai, D., Zhao, T., Fan, Y., Liao, B.: Materials Characterization, 55, 2005, p. 378. doi:10.1016/i.matchar.2005.08.003

[6] Davies, R.: Metallurgical Transactions A, 9, 1978, p. 671. doi:10.1007/BF02659924

[7] Sarwar, M., Priestner, R.: Journal of Materials Science, 31, 1996, p. 2091. doi:10.1007/BF00356631

[8] Movahed, P., Kolahgar, S., Marashi, S., Pouranvari, M., Parvin, N.: Materials Science and Engineering A, 518, 2009, p. 1. doi:10.1016/j.msea.2009.05.046

[9] Bag, A., Ray, K., Dwarakadasa, E.: Metallurgical and Materials Transactions A, 30, 1999, p. 1193. doi:10.1007/s11661-999-0269-4

[10] Sarwar, M., Manzoor, T., Ahmad, E., Hussain, N.: Materials \& Design, 28, 2007, p. 1928. doi:10.1016/j.matdes.2006.05.010

[11] Tüzemen, M. Ç., Salamci, E.: In: Proceedings of 12th Biennial Conference on Engineering Systems Design and Analysis. Copenhagen, ASME 2014, V003T014A 007. doi:10.1115/ESDA2014-20231

[12] Sarwar, M., Ahmad, E., Qureshi, K., Manzoor, T.: Materials \& Design, 28, 2007, p. 335. doi:10.1016/j.matdes.2005.05.019

[13] Salamci, E., Kabakci, F.: Journal of The Faculty of Engineering and Architecture of Gazi University, 26, 2011, p. 263. 
[14] Jeong, W., Kim, C.: Metallurgical Transactions A, 18, 1987, p. 629. doi: $10.1007 / \mathrm{BF} 02649478$

[15] Rakhshkhorshid, M., Sendesi, S.-A. T.: Journal of Iron and Steel Research, International, 21, 2014, p. 246. doi:10.1016/S1006-706X(14)60038-8

[16] Lawson, R. D., Matlock, D. K., Krauss, G.: Metallography, 13, 1980, p. 71 .

doi:10.1016/0026-0800(80)90023-3

[17] Turkish Standard. EN ISO 6892-1. Metallic Materials-Tensile Testing. Part 1.

[18] Sakai, S., Morito, S., Ohba, T., Yoshida, H., Takagi, S.: Journal of Alloys and Compounds, 577, 2013, p. S597. doi:10.1016/j.jallcom.2012.02.027
[19] Speich, G., Demarest, V., Miller, R.: Metallurgical Transactions A, 12, 1981, p. 1419. doi:10.1007/BF02643686

[20] Santofimia, M., Kwakernaak, C., Sloof, W., Zhao, L., Sietsma, J.: Materials Characterization, 61, 2010, p. 937. doi:10.1016/j.matchar.2010.06.006

[21] Korzekwa, D., Matlock, D., Krauss, G.: Metallurgical and Materials Transactions A, 13, 1982, p. 2061. $\underline{\text { doi: } 10.1007 / \mathrm{BF} 02645952}$ 